\title{
A TEORIA DA EMPRESA NO CÓDIGO CIVIL DE 2002 \\ O FIM DA DISTINÇÃO ENTRE SOCIEDADES CIVIS E COMERCIAIS
}

Thiago Spercel

\begin{abstract}
Resumo:
Com a entrada em vigor da Lei n. 10.406, promulgada em 10 de janeiro de 2002 e a unificação da matéria civil e da matéria comercial no mesmo diploma legislativo de direito privado, houve a substituição da "teoria dos atos/atividade de comércio" caracterizadora do Direito Comercial pela "teoria da empresa" que passa a dar contorno ao direito de empresa já adotada internacionalmente. Sem a pretensão de esgotar o tema, a presente exposição pretende analisar as principais características da mencionada "ıeoria da empresa" e suas principais conseqüências, especialmente em função da nova Lei n. 10.406, dentre elas o inegável fim da distinção entre as sociedades civis e as sociedades comerciais.
\end{abstract}

Palavras-chave: Novo Código Civil. Direito de Empresa. Empresário Rural. Pequeno Fmpresário. Falência. Escrituração Mercantil. Sociedades.

\begin{abstract}
:
With the enactment of Law n. 10,406 of January 10, 2002 and the unification of the Civil Law with the commercial law in a same piece of legislation, the so called "acts of commerce theory" peculiar to the former commercial law was replaced by the "enterprise theory" Without the intention of exploring the matter to its exhaustion, this paper intends to scrutinize the main characteristics of the so called "enterprise theory" and its consequences in light of the newly-enacted Law n. 10,406, mainly the end of the distinction of the rules applicable to civil companies and those applicable to commercial companies.
\end{abstract}

Keywords: New Brazilian Civil Code. Business Law. Rural Enterpreneur. Small Enterpreneur. Bankruptcy. Commercial Accuutancy. Partnerships.

1. Introdução

Muito emboru a noção de comércio enquanto intermediuçãu na relação de troc a exista desde a antiguidade, o Direito Comercial, visto como conjunto de normas juridicas, usos e costumes especiais, destinados a regular as atividades profissionais dos comerciantes e as relações juridicas surgidas do exercicio do comércio, tem sua origem no final da Idade Média, com o desenvolvimento do comércio maritimo e a crescente utilização da moeda. F́, nesse periodo que se dá o surgimento dos mercados e feiras, o

Mestrando em Direito Comercial pela l aculdade de Direito da Liniversidade de São Paulo. 
fortalecimento das corporações e o aparecimento dos primeirus institutos e titulos comerciais. $^{\prime}$

Nusse contexto, o Direito Comercial surge como o direito de amparo ao comerciante, vale dizer, assume o Direito Comercial o caráter subjetivo e classista, aplicável unicamente à classe dos comerciantes reunidos em corporações, independente da natureza das relações jurídicas por eles desempenhadas.

Com o espírito ae igualdade defendido pela revolução francesa c com abolição dos privilégios de classe, surgiu o "Code de Commerce" francês de 1807, que passou a definir comerciantes como "os que exercem atos de comércio e deles fazem profissão habitual"

Na mesma linha seguiu o Código Comercial brasileiro de $1850,{ }^{2}$ au dispor, em seu art. $4^{\circ}$, que "ninguém é reputado comerciante sem que faça da mercuncia profissão habitual"

Passou o Direito Comercial, portanto, a assumir o caráter objctivo e ser aplicável não mais à classe dos comerciantes, mas aos atos de comércio e à atividade da mercancia. conceitos essus que lodavia não tinham - nem nunca tiveram definição clara conforme um critério exato ou científico.

Em certas ocasiões, tanto em França ${ }^{3}$ como no Brasil, ${ }^{4}$ houve tentativas de definir os atos de comércio por determinação de lei, porém logo se percebeu que as enumerações legais mostravam-se defeituosas e meramente exemplificativas, ficando a cargo da doutrina e da jurisprudência criar várias teorias que não esclareciam completamente $o$ assunto.

Para a maioria dessas teorias, entendia-se por atos de comércio ou atividade comercial a série de atos conjuntamente considerados, praticados profissionalmente e com habitualidade, visando a circulação de mercadorias com o intuito de lucro. Em outras palavras, seriam requisitos indispensáveis à qualidade de comerciante e à atividade comurcial: (i) a intermediação, consistente na atividade de intermediário entre o produtor e consumidor, ou dito de modo diverso, a interposição na efetivação da troca ou venda de mercadorias; (ii) a especulação, traduzida na atividade econômica com intuito de lucro; e

Como por exemplo a letra de càmbio. o câmbio maritimo e o seguro maritimu.

Lei n. 556, de 25 di junho de 18.50 .

Code du Commerce, arts. 632 e 633

$\mathrm{O}$ art. 19 do Regulamento 737, de 25 de novembro de 1850, dispunha o seguinte: "Considera-se mercancia: $\$ 1^{\circ}$ - A compra c venda ou troca de efcitos móveis ou semoventes para os vender por grosso ou a retalho. na mesma espécie ou manufaturados, ou para alugar o seu uso; $\S 2^{\circ}$ - As operações de câmbio, bancu ou corretagem: $\S 3^{\circ}$-As empresas de fábricas, de comissōes, de depósitos, de expedição, consignação, e transporte de mercadorias, de espetáculos públicos. $\S 4^{\circ}-$ Os seguros, fretamentos, riscos c quaisquer contratos relativos ao comércio maritimo; e $\$ 5^{\prime \prime}$ A armação e expedição de navios" 
(iii) a profissionalidade, que significa a prática habitual. coordenada e repetida dos atos do comércio.

Em função da referida dificuldade de caracterização e do desenvolvimento da economia moderna, o conceito de Direito Comercial baseado na figura do comerciante tem sido gradativamente substituído pelo direito de empresa, que regula as atividades das empresas, dos empresários e dos istabelecimentos.

Além disso, vale lembrar que o Direito Comercial c o Direito Civil são distintos ramos do direito privado, que todavia não se confundem. Não-obstante, tem havido, nos últimos tempos, diversas tentativas de unificação do Direito Civil ao Direito Comercial num só diploma legal, preservando-se, contudo, as normas e principios autônomos aplicáveis a cada um desses ramos. 'São exemplos de tentativas de unificação o Projeto de Código de Obrigaçôes, de 1965, e o Projeto de Código Civil, de 1975, sob a supervisão do Prof. Miguel Reale, projeto esse convertido na Lei n. 10.406, promulgada em 10 de janeiro de 2002, a qual nesta exposição chamaremos, para facilidade de referência, "Código Civil de 2002" Com a entrada em vigor do Código Civil de 2002, foram revogados a Lei n. 3.071, de $1^{\circ}$ de janciro de 1916 ("Código Civil de 1916") e a Parte Primeira da Lei n. 556, de 25 de junho de 1850 ("Código Comercial de 1850"), bem como derrogado o Decreto n. 3.708, de 10 de janeiro de 1919.

Além de unificar a matéria civil e comercial no mesmo diploma, o Código Civil de 2002 inovou em substituir o Direito Comercial e a teoria dos atos de comércio pelo direito de empresa constante em seu Livro Il e pela mais moderna "leoria da empresu" já adotada e defendida internacionalmente.

Feitas essas explicações iniciais e sem a pretensão de esgotar o tıma, a presente exposição pretende analisar as principais características da mencionada "teoria da empresa" e suas principais conseqüências, especialmente em função do Código Civil de 2002, dentre elas o inegável fim da distinção entre as sociedades civis e comerciais.

2. As diversas acepções da "Empresa" e do "Empresário"

Embora muitos já tenham arriscado estabelecer uma definição precisa sobre o conceito de "empresa" ' parece-nos ser o professor Alberto Asquini, em obra traduzida

\footnotetext{
MARTINS, Fran. Curso de Direito ('omercial. 23. ed. Rio de Janeiro: Forense, 1999. p. 26.

O professor italiano Cesare Vivante conceituava empresa como um organismo econòmico que sob seu próprio risco recolhe e pōe em atuaçào. sistematicamente. os elementos necessários para obter um produto destinado à troca. A combinação de fatores - natureza, capital e trabalho - que, associados, produzem resultados impossiveis de se obter caso fossem divididos, e o risco, que o empresário assume ao produzir nova riqueza, são segundo ele os requisitos indispensáveis a toda empresa. Já para o professor Alfredo Rocco, também italiano, somente haveria empresa quando a produção é obtida mediante trabalho dos uutros.
} 
e comentada pelo ilustre professor Fábio Konder Comparato, ${ }^{8}$ quem esclarece o assunto com maior sucesso. Compartilha do mesmo entendimento o professor Sylvio Marcondes, autor da Exposição de Motivos do Anteprojeto de Código das Obrigações, de 1965.

Segundo tais autores, sob o aspecto econômico é de fato possível estabelecer uma definição unitária da empresa, como sendo a organização de trabalho e capital que tem como fim a produção de bens ou serviços para a troca. Porém, sob o aspecto juridico, o conceito de empresa é o conceito de um fenômeno econômico poliédrico, que assume não somente um, mas diversos perfis. segundo o fenômeno econômico e a norma jurídica a qual se refere.

Em primeiro lugar, o vocábulo "cmpresa" pode assumir um perfil subjetivo. como decorrência da igura do "empresário", titular da empresa, pessoa (fisica ou jurídica) que exerce, profissionalmente, de modo habitual e sistemático e em nome próprio, uma atividade econômica organizada, tendo por fim a produção ou a troca de bens ou serviços, organizando e coordenando fatores de produção e assumindo o risco técnico e econômico correlato. Nesse sentido, não é empresário quem exerce atividade econômica às custas e sob o risco de terceiros, como ć o caso do representante ou do administrador. Também não é empresário quem presta um trabalho de caráter exclusivamente pessoal ou exerce profissão intelectual, a menos que sua atividade seja organizada sob a forma de atividade organizada de empresa.

O vocábulo também pode assumir o perfil funcional, enquanto atividade econômica destinada à produção ou circulação de bens ou serviços.

Além disso, importante mencionar o perfil patrimonial da empresa, que se reporta ao conceito de patrimônio especial e destacado do empresário, constituido pelo complexo de bens que o empresário se vale para o exercício de sua atividade empresária, também chamado de estabelecimento.

Também há, por fím, o perfil corporativo da empresa. segundo o qual a empresa é uma instituição, que se define pela organização de pessoas embasada em relações de hierarquia e cooperação entre seus membros, em função de um escopo comum. A empresa-instituição é formada pelo empresário e pelos empregados e colaboradores (dirigentes, funcionários e operários). Colocado de forma diversa, é uma

ou, por outras palavras, quando o empresário recruta trabalho. o organiza, fiscaliza e retribui e o dirige para os fins da produção. Já nas lições de J. X. Carvalho de Mendonça, empresa é a organização técnicoeconômica que se propõe a produzir, mediante a combinação dos diversos elementos, natureza, trabalho e capital, bens ou serviços destinados ì troca, com a esperança de realizar lucros, correndo os riscos por conta do empresário, isto é, daquele que reúne, coordena e dirige esses ulementos sob a sua responsabilidade.

7 ASQUINI, Alberto. Protili dell'Impresa. Revista Del Diritlo Commerciale, v. 4I, n. 1, 1943.

8 COMP.ARA'IO. Fabio Konder. Perlis da Empresa. Revista de Direito Mercantil, v. 104.

9 MARCONDES, Sylvio. Questões de Direito Vercantil. São Paulo: Saraiva, 1997. 
pluralidade de pessoas ligadas entre si por relações individuais de trabalho com um fïm individual, formando, contudo, um núcleo social organizado em função de um fim econômico comum. Nesse sentido, a organização se realisa através da hicrarquia das relações entre o empresário, dotado do poder de mando, e seus colaboradores, sujuitos à subordinação e fidelidade em prol do interesse comum. Ressalte-se, contudo, que o reconhecimento de uma organização de pessoas como instituição não necessariamente significa sua personificação.

Vale também o registro da posição de respeitados autores que afirmam que a umpresa é o agente econômico do mercado, entendendo-se por mercado o ambiente jurídico-institucional em que se concretizam as transações econômicas, o lugar artificial que a lei constrói, governa, orienta e controla. ${ }^{10}$ Nessa linha, o direito empresarial regularia a relação entre duas empresas com o propósito de produzir e disponibilizar bens e serviços no mercado. de forma massificada e impessoal, disputando clientela e market share com outra empresa concorrente; em outras palavras, as empresas seriam entidades que orientam sua atividade profissional e econômica em função do mercado.

Como já mencionado anteriormente, o vocábulo "empresa" no mundo jurídico, assumirá um dos diversos perfis econômicos, conforme a situação fática c o norma legal a que se refira. A título exemplificativo, para esclarecimento dos conceitos acima reportados, podemos citar: ${ }^{\prime}$

(a) 0 art. $2^{\circ}$ da Consolidação das Leis do Trabalho, ao estabelecer que "considera-se empregador a empresa individual ou coletiva que, assumindo us riscos da atividade econômica, admite, assalaria e dirige a prestação pessoal de serviços", claramente utilizou o vocábulo empresa sob o perfil do empresário empregador, seja ele pessoa fisica ou juridica:

(b) os artigos 16 e 17 da Lei de Defesa da Concorrência (Lei n. 8.884. de II de junho de 1994) utilizou o vocábulo empresa enquanto sujcito de direitos e obrigações, ao estabelecer que "as diversas formas de infração da ordem econômica implicam a responsabilidade da empresa e a responsabilidade individual de seus dirigentes ou administradores, sulidariamente" e "serão solidariamente responsáveis as empresas ou entidades integrantes de grupo econômico, de fato uu de direito, que praticarem infração da ordem econômica";

(c) ainda na Lei de Defesa da Concorrência, o art. $20 . \S \S 2^{\circ}$ e $3^{\circ}$, vale-se do perfil da empresa entidade enquanto agente economico do mercado ao dispor que "ocorre posição dominante quando uma tmpresa ou grupo de empresas controia parcila suhstancial de mercado relevante, como fornecedor, intermediárin, adquirente ou financiador de um produto. serviço ou tecnologia a ele relativa" e "a posição dominante a que se

\footnotetext{
10 IRTI, Natalino. Teoria Generale del Diritto e Problema del Mercato. Revista di Diritho Civile v. 1. n. 14: Concetto Giuridico di Mcrcado e Dovere de Solidarietá. Revista di Diritlo Civile, v. 2, n. 185.

"MARCONDES, Sylvio, ob. cit.
} 
refere o parágrafo anterior é presumida quando a empresa ou grupo de empresas controla 20\% (vintc por cento) de mercado relevante, podendo este percentual ser alterado pelo CADE para setores especificos da economia. No mesmo sentido de agente econômico do mercado. o art. 21, IV, da Lei de Defesa da Concorrência, que configura infração da urdem econômica limitar ou impedir o acesso de novas empresas au mercado":

(d) o art. 448 da mesma Consolidação, por outro lado, ao estabelecer que "a mudança na propriedade ou na estrutura jurídica da empresa não afetará os contratos de trabalho dos respectivos empregados" utilizou o perfil patrimonial da empresa, enquanto estabelecimento; e

(e) o art. 165 da Constituição Federal, que diz que “a Constituição assegura aos trabalhadores: V - integração na vida e no desenvolvimento da empresa, com participação nos lucros e, excepcionalmente, na gestão, segundo for estabelecido em lei" reporta-se ao perfil corporativo da empresa, enquanto instituição.

As lições dos professores Asquini e Comparato nos permitem afirmar que o vocábulo "empresa" não somente assume diversos significados nos diversos diplomas legais, como também entrou no Código (ivil, de 2002, com diversos perfís econômicos distintos, cabendo ao intérprete aclarar seu significado especifico onde a palavra foi utilizada, por prática de linguagem ou por pobreza de vocabulário, de maneira imprecisa.

Nesse sentido, podemos elencar como excmplos de empresa sob o perfil subjetivo do empresário no Código Civil, de 2002, os seguintes artigos, sem destaque no original:

Art. 966 - Considera-se empresário quem exerce
profissionalmente atividade econômica organizada para a
produção ou a circulação de bens ou de serviços. Parágrafo
único. Não se considera empresário quem exerce profissão
intelectual, de natureza cientifica, literária ou artística, ainda
com o concurso de auxiliares ou colaboradores, salvo se o
exercício da profissão constituir elemento de empresa; e
Art. 931 . Ressalvados outros casos previstos em lei
especial, os empresários individuais e as empresas
respondem independentemente de culpa pelos danos
causados pelos produtos postos em circulação.

Do mesmo modo. exemplificamos casos do perfil funcional da empresa enquanto atividade empresária no Código Civil, de 2002, com nossa ênfase:

Art. 974. Poderá o incapaz, por meio de representante ou devidamente assistido, continuar a empresa antes exercida por cle enquanto capaz, por seus pais ou pelo autor de herança. $\S 1^{\circ}$ Nos casos deste artigo, precederá autorização judicial, após exame das circunstâncias e dos riscos da empresa, bem como da conveniência em continuá-la, 
podendo a autorização ser revogada pelo juiz, ouvidos os pais, tutores ou representantes legais do menor ou do interdito, sem prejuízo dos direitos adquiridos por terceiros. $\S 2^{\circ}$ Não ficam sujeitos ao resultado da empresa os bens que. o incapaz já possuía, ao tempo da sucessão ou da interdição, desde que estranhos ao acervo daquela, devendo tais fatos constar do alvará que conceder a autorização:

Art. .085 . Russalvado o disposto no art. 1.030, quando a maioria dos sócios, representativa de mais da metade do capital social, entender que um ou mais sócios estão pondo em risco a continuidadc da empresa, em virtude de atos de inegável gravidadi, poderá excluí-los da sociedade, mediante alteração do contrato social, dusde que prevista neste a exclusão por justa causa;

Art. 1.155. - Considera-se nome empresarial a firma ou a denominação adotada, de conformidade cum este Capitulo. para o exercício de empresa;

Art. 1.172. - Considera-se gerente o preposto permanente no exercicio da empresa, na sede desta, ou em sucursal, filial ou agência.

Art. 1.178. Os preponentes são rúsponsáveis pelos atos de quaisquer prepostos, praticados nos seus estabelecimentos e relativos à atividade da empresa, ainda que não autorizados por escrito; e

Art. 1.184. Nu Diário serão lançadas, com individuação, clareza e caracterização do documento respectivo, dia a dia, por escrita direta ou reprodução, todas as operações relativas ao exercício da empresa.

Também é possível localizar, no Código Civil, de 2002, o vocábulo "empresa" sob seu perfil patrimonial de estahelecimento, com destaques nossos:

Art. 978. O empresário casado pode, sem necessidade de outorga conjugal, qualquer que scja o regime de bens, alienar os imóveis que integrem o patrimônio da empresa ou gravá-los de ônus real.

Pode-se, inclusive, identificar o perfil corporativo-institucional da empresa no Código Civil, de 2002:

Art. 931. Ressalvados outros casos previstos em lei especial, os empresários individuais e as empresas respondem independentemente de culpa pelos danos causados pelos produtos postos em circulação. 
3. A caracterização do empresário no Direito de Empresa

Para fins do Direito de Empresa constante no Livro Il do Código (ivil de 2002, assim é caracterizada a figura do empresário:

Art. 966. Considera-se empresário quem exerce profissionalmente atividude económica organizada para a produção ou a circulação de hens ou de serviços.

A dufinição da figura do empresário, dada em relação ao empresário pessoa física, para nós é importante para entender o conceito básico, e depois aplicar às sociedades, distinguindo-as em empresárias ou não-cmpresárias.

Em primeiro lugar, trata-se de atividade econômica, isto é, atividade referente à criação de riquezas, bens ou serviços, de modo que aquele que exerce qualquer atividade que não seja econômica com o fim de produzir riquezas não é empresário.

Em segundo lugar, deve a atividade ser organizada, em outras palavras, atividade em que se coordenam e organizam os diversos fatores da produção: trabalho. nature $<$ a e capital.

Finalmente, deve ser uma atividade profissional, ou seja, dotada de habitualidade e sistemática em sua prática, e realizada em nome próprio.

\subsection{Os profissionais intelectuais}

Há, porém, pessoas que exercem profissionalmente uma atividade criadora de bens ou serviços, mas não devem e não podem ser consideradas empresárias. Isto é o que vem disposto no parágrafo único do art. 966 acima citado:
Art. 966 Parágrafo único. Não se considera empresário quem exerce profissão intelectual, de natureza cientifica. literária ou artística, ainda com o concurso de auxiliares ou colaboradores, salvo se o exercicio da profissão constituir clemento de empresa.

Nesse sentido, à atividade do profissional intelectual acima referida falta 0 elemento de organização de fatores. já que a atividade mental criativa é a base de toda sua atividade. Portanto, não podem, embora sejam profissionais e produzam bens ou serviços. ser considerados empresários, exceto se organizarem os fatores de produção (trabalho, capital e pessoas) em empresa e assumirem a veste de empresários.

Parece um exemplo claro, segundo o prof. Sylvio Marcondes, ${ }^{12}$ a posição do

12 MARCONDES, Sylvio, ob. cit. 
médico, o qual, quando individualmente opera, faz diagnóstico ou presta consultas, está prestando um serviço resultante de sua atividade intelectual, e por isso não é empresário. Entretanto, se ele organiza fatores de produção, isto é, une capital, trabalho de outros médicos, enfermeiros e ajudantes. e se utiliza de imóvel e equipamentos para a instalação de um hospital, então o hospital é a empresa e o dono ou titular desse hospital, seja pessoa física ou juridica, será considerado empresário, porque está organizando fatores de produção para produzir scrviços.

\subsection{O empresário rural e o pequeno empresário}

O Código ('ivil, de 2002 estabelece o tratamento facultativo de empresário ao empreendedor rural, uma vez que, segundo o art. 907, "pode o empresário requerer inscrição no Registro Público de Eimpresas Mercuntis da respectiva sede, caso em yue ficará equipurado, paru todos os efeitos, ao emprescírio sujeito a registro"

Além disso, considerando a vastidão territorial e as diversidades regionais. entenderam os legisladores pátrios, no art. 970 do Código Civil, 2002, destinar tratamento difurenciado ao empresário rural e o pequeno emprusário, dispondo que "a lei assegurará tratamento favorecido, diferenciado e simplificudo ao empresário rural e ao pequéno empresário, quanto à inscrição e aos efeitos dai decorrentes" Ressalte-se que estamos aqui diante de norma aberta, cuja implementação dependerá de normas juridicas acessórias a serem emitidas pelo Departamento Nacional de Registro do Comércio, DNRC.

\subsection{As sociedades}

Chegamos, finalmente, ao ponto central da presente exposição: a nova forma de classificação das sociedades. Para fins de uma melhor comprcensão, propomonos a classificar as sociedades quanto à forma de organização de sua atividade, em primeiro lugar, e quanto ao seu tipo jurídico, depois. A redação do Código Civil, de 2002, parece utilizar, inadvertidamente, o vocábulo "sociedade simples " em ambos os critérios de classificação, como se sinônimos fossem. Para fins desta exposição, entretanto, passaremos a utilizar "sociedades simples" para nos referir ao tipo juridico. e "sociedades não-empresárias" para as sociedades que não se organizam sob a forma de empresa.

(a) quanto à forma de organização da atividude:

Na vigência do Código Civil, de 1916, classificavam-se, as sociudades, em "comerciais" ou "civis" conforme realizassem atividades de comércio ou da murcancia, 
no primeiro caso, e por exclusão todas as demais atividades, no segundo caso, exceção feita às sociedades por ações. que eram consideradas mercantis independente de seu objeto (art. $2^{\circ} \$ 1^{\circ}$ da Lei n. 6.404, de 15 de dezembro de 1976, conforme posteriormente alterada).

Com a entrada em vigor do Código Civil, de 2002. ficou extinta a diferenciação entre sociedades "civis" e "comerciais" Nesse sentido, Miguel Reale, ${ }^{13}$ na Exposição de Motivos de 1975, afirma que "o tormentoso e jamais claramente determinado conceito de "ato de comércio" é substituido pelo de "empresa" assim como a categoria de "fundo de comércio" cede lugar à de "estabelecimento" Fica superada de vez a categoria imprópria, ora vigente, de "sociedade civil de fins econômicos", pois, no âmbito do Código Civil unificado, são civis tanto as associações como as sociedades, qualquer que seja a forma destas. Distinguem-se apenas as sociedades em simples ou empresárias, de conformidade com o objetivo econômico que tenham em vista e o modo de seu exercício"

Passam as sociedades a serem classificadas, quanto à forma de sua organização, em "empresárias" e "não-empresárias" independente de seu tipo jurídico, 14 conforme segue com nossos grifos:

Art. 982. Salvo as exceções expressas, considera-se empresária a sociedade que tem por objeto o exercicio de atividade própria de empresário sujeito a registro (art. 967); e, simples, as demais.

Parágrafo único. Independentemente de seu objeto, considera-se empresária a sociedade por ações; ๖, simples, a cooperativa.

Percebe-se, portanto, que as noções de "empresa". "atividade empresária" e "empresário" passaram a classificar as sociedades quanto à forma de sua organização em "empresárias" de um lado, e "não-empresárias" de outro, conforme tenham sua atividade organizada para produção de bens ou serviços, com a coordenação dos fatores da produção, e dotada de habitualidade e sistemática.

Nota-se. também, que além de manter a exceção das sociedades por ações enquanto socicdades empresárias independente de seu objeto, o Código Civil, de 2002, também excepcionou as sociedades cooperativas, que serão sempre não-empresárias, não importando sua atividade e forma de organização.

\footnotetext{
13 REALE, Miguel. Exposição de Motivos do Supervisor da ('omissāo Revisora e Elaboradora do Código Civil

it REALE, Miguel, ob. cit.
} 


\section{(b) quanto ao tipo juridico:}

Sob o regramento anterior, os principais tipos jurídicos adotados pelas sociedades eram a sociedade $\mathrm{cm}$ nome coletivo, a sociedade em comandita simples, a sociedade de capital e indústria, a sociedades em conta de participação, a sociedade por quotas de responsabilidade limitada, a sociedade anônima, a sociedade em comandita por ações e a sociedade cooperativa, podendo qualquer uma delas, por força do artigo 1.364 do Código ('ivil, de 1916, exercer tanto a atividade civil como comercial, exceção feita à sociedade anônima e à sociedade em comandita por ações, que assumiam a qualidade de sociedades mercantis independente de sua atividade.

Com o advento do Código Civil. de 2002, a matéria passou a ser regulada de forma diversa, aqui reproduzida:

Art. 983 - A sociedade empresária deve constituir-se segundo um dos tipos regulados nos arts. 1.039 a 1.092; a sociedade simples pode constituir-se de conformidade com um desses tipos, e, não o fazendo, subordina-se às normas que lhe são próprias.

Parágrafo único. Ressalvam-se as disposições concernentes à sociedade em conta de participação e à cooperativa. bem como as constantes de leis especiais que, para o exercício de certas atividades. imponham a constituição da sociedade segundo determinado tipo.

De acordo com o artigo acima reproduzido. a sociedade que exerce atividade empresária pode se revestir dos tipos juridicos regulados no arts. 1.039 a 1.092. que são, a sociedade em nome colctivo, a sociedade em comandita simples, a sociedade limitada, a sociedade anônima e a sociedade em comandita por ações.

De modo diverso, a sociedade não-empresária pode também constituir-se de acordo com um desses tipos jurídicos elencados nos arts. 1.039 a 1.092 (a sociedade em nome coletivo, a sociedade em comandita simples, a sociedade limitada. a sociedade anônima e a sociedade eın comandita por ações), porém, em não o fazendo, subordinarse-á às normas de sociedades de tipo juridico simples.

As principais conclusões lógicas a que chegamos diante de tais afirmações são as seguintes:

(a) as sociedades empresárias não podem assumir o tipo jurídico de sociedades simples nem tampouco de cooperativas, sendo-lhes facultados todos os demais tipos;

(b) as sociedades não-empresárias podem adotar qualquer tipo jurídico, incluindo o de sociedade simples e cooperativa; e 
(c) as sociedades não-empresárias, ao adotarem os tipos de sociedades por ações ou em comandita por ações, por força de lei, perderão sua característica de não-empresárias e passarão a ser consideradas sociedades empresárias, com as conseqüências daí advindas.

Valı mencionar, também, que não existe mais previsão acerca da sociedade de capital e indústria anteriormente prevista no Código Civil, de 1916, sendo lícito portanto concluir pela extinção do referido tipo jurídico, ficando todavia permitida a contribuição de serviços ao capital de sociedades simples.

Caso interessante é o das sociedades de advogados, que são sociedades profissionais regidas por lei especial (Lei n. 8.906, de 4 de junho de 1994) e estatuto próprio, lei essa que estabelece a necessidade de constituição sob o tipo jurídico de sociedade civil de prestação de serviço de advocacia.

Estamos nesse caso diante da exceção prevista no art. 983, § único, do Código Civil, de 2002, que ressalva somente o tipo jurídico da sociedade, sem se reportar ao objeto, atividade ou forma de organização. É permitido concluir. em princípio, que as sociedades de advogados, muito embora devam conservar seu tipo jurídico previsto na Lei n. 8.906, poderão - e deverão ser classificadas como empresárias ou não-empresárias, conforme tenham sua atividade organizada para produção de bens ou serviços, com a coordenação dos fatores da produção, e dotada de habilualidade e sistemática.

Todavia, mesmo que empresária, por força do disposto no art. $19, \S \S 1^{\circ}$ e $2^{\circ}$, da Lei n. 8.906, de 4 de junho de 1994, a sociedade de advogados não se vinculará ao Registro de Empresas das Juntas Comerciais ou ao Registro Civil das Pessoas Jurídicas. mas efetuará o registro de seus atos constitutivos no Conselho Seccional da Ordem dos Advogados do Brasil em cuja base territorial tiver sede. Ficará, entretanto. obrigada pelas demais obrigações dos empresários como, por exemplo. a escrituração e contabilidade. e terá, eventualmente, legitimidade para falência, concordata e reorganização judicial, conforme discutido no item IV.3, abaixo.

\section{Principais conseqüências}

\subsection{O registro das Sociedades Simples e Empresárias Lei n. 8.934, de 18.11.1994}

Na vigência do sistema anterior, o registro dos atos constitutivos e demais documentos das sociedades comerciais, para garantia da oponibilidade a terceiros, era regulado pela Lei n. 8.934, de 18 de novembro de 1994, conforme regulamentada pelo Decreto n. 1.800 , de 30 de janeiro de 1996. que determinava que o registro público de 
empresas mercantis e atividades afins seria exercido pelo Deparlamento Nacional de Registro do Comércio (com funções coordenadora e supervisora) e pulas Juntas Comerciais (com função executora).

Apesar de a Lei n. 8.934 e o Decreto n. 1.800 terem recepcionado a teoria da empresa ao se referirem não mais ao "registro do comírcio" mas sim ao "registro público de empresas mercantis", tal recepção foi feita de mancira bastante tímida e pouco eficiente, 15 uma vez que ainda fica evidente a necessidade da existência da "mercancia" atividade do comerciante - para se proceder com o registro nos termos daquela Lei e Decreto.

No sentido oposto, fícava a cargo dos Cartórios de Registro de Pessoas Jurídicas o registro das sociedades clue desempenhassem atividades "civis" ou seja. por exclusão, não-comerciais. $^{16}$

Vem agora o Código Civil, de 2002 dispor de modo diverso. como se lê a seguir:
Art. 1.150. O empresário e a sociedade empresária vinculam-se ao Registro Público de Empresas Mercantis a cargo das Juntas Comerciais. e a sociedade simples ao Registro Civil das Pessoas .Juridicas, o qual deverá obedecer às normas fixadas para aquele registro. sc a sociedade simples adotar um dos tipos de sociedade empresária.

Fica, portanto. definitivamente esclarecido que nào é mais a atividade do comércio que definc o órgão competente para efetuar os registros das sociedades, mas sim a atividade empresária. Desta mancira, para fins de registros dos documentos societários. não existe mais a distinção entre sociedades civis ou comerciais, mas somente entre sociedades empresárias e não-empresárias (ou simples. conforme a turminologia da I.ci).

Por oportuno, cumpre-nos esclarecer que a atividade empresária engloba a atividade comercial, mas a ela não se limita. $\mathrm{O}$ ato empresarial é muito mais amplo que o ato do comércio por envolver qualquer atividade produtiva relacionada à circulação de bens e serviços de forma organizada e profissional. e não somente a intermediação na compra e venda de mercadorias. Por esse motivo. existe um sem número de sociedades civis, atualmente registradas em Cartórios Civis de Registro de Pessoas Jurídicas, que são organizadas como empresas e que, portanto, deverão passar a manter seus registros perante as Juntas Comerciais. Esse é o caso, por exemplo, de diversas sociedades prestadoras de serviços não regulamentados, incluindo as prestadoras de serviços

\footnotetext{
is Em que pese a opiniào de Jorge Rubem Folena de Oliveira, em Desenvolvimenro da Teoria da Empresa Fim da Distinçào entre Sociedades Civis e Comerciais. Revista de Direito Mercantil. p. 37. 
administrativos para terceiros, de transporte de valores, cargas e passageiros, de administração de cartões de crédito e meios de pagamentos, de beneficiamento de materiais, de processamento de dados, entre muitas outras.

As sociedades civis que tiverem seus atos registrados junto aos Cartórios Civis de Registro de Pessoas Jurídicas, e que se enquadrarem no conceito de empresa acima apresentado, terão o prazo de um ano, a partir da entrada em vigor do Código Civil de 2002, para escolher um dos tipos jurídicos empresárias e adaptar seus contratos sociais $^{17}$ o que inclui a migração para a Junta Comercial competente. ${ }^{18}$ Caso, entretanto, decidam implementar qualquer modificação de seus atos constitutivos ou registrar outro ato societário antes disso, terão de antecipar tal prazo e imediatamente adaptar seus contratos sociais, o que inclui a migração para a Junta Comercial competente. ${ }^{19}$

Por fim, somos da opinião de que nem a Lei n. 8.934/94, nem o Decreto $n$. 1.800. foram revogados com a entrada em vigor do Código Civil, de 2002. O novo código apenas aumentou o espectro de abrangência dos referidos normativos, que continuam vigentes para regular o registro público de todas as empresas e não somente empresas mercantis bem como a organização e funcionamento do DNRC e Juntas Comerciais. Nova regulamentação sobre o tema deverá ser emitida pelo DNRC em breve.

\subsection{Valor probante dos livros e fichus de escrituração mercantil}

Nos termos do Código Comercial de 1850 e regulamentação correlata, os comerciantes eram obrigados a manter regulares sua escrituração e contabilidade, seguindo certas formalidades prescritas por lei. Obedecidas tais formalidades, os livros e fichas de escrituração mercantil eram dotados de valor probante pleno em favor do comerciante, $c$ merecedores de fé pública. ${ }^{20}$

Agora, a obrigação de escrituração e contabilidade passa a se aplicar a todas as empresas e empresários, nos termos dos arts. 1.179 a 1.195 do Código Civil, de 2002. Não se conservou, todavia, a previsão quanto ao valor probante pleno e a fé pública de tais livros e fichas de escrituração mercantil, cabendo a indagação se a partir de agora o empresário gozará de valor probante e fé pública em seus documentos.

Art. 2.031 do Código (ivil, de 2002.

18 A migração dos registros para as Juntas Comerciais implicará na redução de despesas e burocracias, na medida $\mathrm{em}$ que nas Juntas Comerciais as taxas de arquivamento são lixas, admitem-se documentos lavrados sob a forma sumária e não se requer o reconhecimento de assinaturas, ao passo em que os Cartórios de Registro Civil das Pessoas Iuridicas cobram suas taxas com base no valor do documento e não admitem documentos lavrados na forma sumária e sem riconhecimento de assinaturas.

Art. 2.033 do Código Civil. de 2002.

20 Art. 23 do Código Comercial, de 1850 e art. $8^{\circ}$ do Decreto-lei n. 486, de 3.3.1969. 


\subsection{Legitimidade para falência e recuperação judicial e extrajudicial}

$\mathrm{Na}$ vigência da Lei n. 7.661, de 21 de junho de 1945, que regulava os institutos da falència e das concordatas preventiva e suspensiva, somente podiam ser considerados falidos os comerciantes regulares (e pessoas equiparadas por Lei) e os de fato. Por sua vez, somente podiam impetrar concordata os comerciantes (e pessoas equiparadas por Lei) que comprovassem sua condição de comerciante regular, por meio da exibição dos livros e documentos comerciais, revestidos das formalidades legais de registro. A insolvência das pessoas e sociedades não-comerciantes se sujeitava ao processo de insolvência civil regulado no Código de Processo Civil (arts. 748 a 786).

Com a nova teoria da empresa do Código Civil de 2002. caíram em desuso os conceitos de comerciante e sociedades comerciais, com a substituição pelos conceitos de empresários e empresas, que passaram até mesmo a estar obrigados a manter escrituração e contabilidade dotados de formalidades especiais.

Atualmente, com a entrada em vigor da nova Lei de Falências e Recuperação de Empresas (Lei n. 11.101, de 9 de fevereiro de 2005), a teoria da umprusa foi recepcionada no texto normativo, que passa a dispor sobre a recuperação judicial, a recuperação extrajudicial e a falência do "empresário" e da "sociedade empresária" 21

\section{Conclusão}

Em linha com a tendência mundial, veio em bom momento a alteração da legislação brasileira para recepcionar a teoria da empresa no Código Civil, de 2002, em substituição à já defasada e sempre confusa teoria dos atos de comércio. Como todo processo de mudança, no entanto, tal substituição está causando, num momento inicial, dúvidas e incertezas que deverão ser esclarccidas por legislação complementar, bem como pela doutrina e jurisprudência. Acima de tudo, espera-se das autoridades judiciais e administratis as brasileiras e de todos os operadores do Direito bom senso ao tratar das opiniões ainda não-sedimentadas.

São Paulo, dezembro de 2005.

21 O art. 2.037 do Código Civil de 2002 estabelece a aplicação aos empresários e às sociedades empresariais das disposições de lei não revogadas pelo Código Civil de 2002 reficrentes aos comerciantes. sociedades comerciais e atividades mercantis. portanto, a partir da entrada $\mathrm{cm}$ vigor do Código Civil de 2002. a legislação falimentar já scria aplicável ao empresário e a sociedade empresária antes mesmo da entrada cm vigor da Lei n. 11.101/2005. 


\section{Referências}

ASQUINI, Alberto. Profili dell'Impresa. Revista Del Diritto Commerciale, v. 41, n. I, 1943.

COMPARATO, Fabio Konder. Perfis da Fmpresa. Revista de Direito Mercantil, v. 104.

IRTI. Natalino. Teoria Generale del Diritto e Problema del Mercato. Revista di Dirilto Civile v. $1, \mathrm{n}$. 19.

Concetto Giuridico di Mercado e Dovere de Solidarietá. Revista di Diritto Civile, v. 2, n. 185.

MARCONDES, Sylvio. Questões de Direito Mercantil. São Paulo: Saraiva, 1997.

MARTINS, Fran. Curso de Direito Comercial. 23. ed. Rio de Janeiro: Forunse, 1999. 